\title{
Health and Sickness Absence in Denmark: A Study of Elderly-Care Immigrant Workers
}

\author{
Isabella Gomes Carneiro • Adriana Ortega • \\ Vilhelm Borg • Annie Høgh
}

Published online: 7 November 2008

(c) The Author(s) 2008. This article is published with open access at Springerlink.com

\begin{abstract}
The objective of this study is to investigate patterns of sickness absence in light of health status among immigrants. Cross-sectional data from 2005 was used and the study population consisted of 3,121 healthcare assistants and healthcare helpers working in the elderly-care sector in Denmark. A multinomial logistic regression was employed to investigate the relationship between health indicator, sickness absence and being an immigrant. Our findings show that, on one hand, immigrants have worse health status, but on the other, they have significantly lower sickness absence than their Danish counterparts, even after factors such as age and gender are controlled for. The results show that the relationship between being an immigrant and sickness absence differs according to health status. Our findings are in line with Steer and Rhode's theoretical framework, according to which attendance to work is a function of ability and motivation to be at work.
\end{abstract}

Keywords Immigrants · Elderly-care $\cdot$ Sickness absence . Health

\section{Introduction}

Changes in the demographic profile of the population in Denmark have revealed a series of challenges to the society, among them that of integrating immigrants into the

The present manuscript has not been published elsewhere nor is it under submission elsewhere. Furthermore, there is no conflict of interest in regards to it.

I. G. Carneiro $(\bowtie) \cdot$ A. Ortega $\cdot$ V. Borg · A. Høgh

The National Research Centre for the Working Environment, Lersø Parkallé 105, 2100 Copenhagen, Denmark

e-mail: igc@nrcwe.dk labor market. There have been increasing efforts to recruit immigrants into the elderly-care sector. As results of these efforts, the proportion of immigrants working in the elderly-care sector, as well as the number of immigrants pursuing elderly-care technical education in Denmark has grown considerably in the past years [1]. Nonetheless, along with such efforts, comes the need for learning and better understanding their attachment to the labor market (e.g. integration and participation), work conditions, performance and quality of work.

Furthermore, the changes in the population and in the labor force in Denmark have also generated political interest in regards to sickness absence issues. That is because, as the workforce ages, the lack of replacement increases, leading towards a considerable decrease in the workforce and increase in demands upon those in the labor market. It can also be argued that these factors could, in turn, affect the sickness absence patterns, creating further pressure on the welfare system [2].

Sickness absence is a complex phenomenon with large differences in terms of age, gender, cultural background and social-economical factors, among others [3-5]. The consequences of sickness absence can be detrimental in terms of the economic costs to the society in a general level. It can also affect negatively the individual's life in terms of, unemployment, personal finances, social relations, work relations and lifestyle [6].

Possibly due to the difficulty in terms of sample size and the relatively recent interest in ethnic groups in Scandinavian countries, there have been few quantitative analyses of sickness absence patterns of immigrants in these countries and no comprehensive analysis in Denmark. Nonetheless, there are studies that have looked into disability pension among immigrants in Sweden and Norway [7, 8]. Both of these studies reported a significant higher risk of disability 
pension among immigrants. Nilsson [9] has studied absence in Sweden and found higher absence among immigrants. Similarly, Gustafsson and Österberg [10] found a higher frequency of early retirement among immigrants than among the Swedish nationals. They also found that immigrants have more sick-leaves than Swedish-born individuals. Contrary to such findings, a qualitative study in 10 companies in Denmark concludes that immigrants have lower sickness absence than Danes [11].

The overall public opinion, as presented by the media, is that the group of immigrants is a particularly stable and reliable workforce [12, 13]. A survey from the Danish Chamber of Commerce shows that among the 150 companies interviewed, immigrants are perceived as motivated, willing to learn and service minded [14]. In terms of sickness absence, Copenhagen municipality has observed that immigrants working in the elderly-care sector institutions have almost five less sick absent days, on average, than their Danish work colleagues. As mentioned by one of the leaders in an elderly center, the results are not surprising. She attributes such difference to the fact that: '...the elderly-care sector is a typically female sector and a portion of the sickness absence can be due to sick children at home. In my experience, the ethnic worker has a better family network that helps with the family.' Another factor mentioned is that immigrants have a different relation to the elderly and live with them in a different manner. Hence, the work burden is possibly different between Danes and immigrants [13].

There are some studies in Denmark and in other Scandinavian countries that show comparatively higher prevalence of diabetes and heart-and-respiratory-system diseases among immigrants [15]. Previous studies also indicate that immigrants tend to report worse health than the general host country population [16]. Accordingly, studies show that immigrants use the health care system more often than Danes [15]. Hence, the assumption that immigrants take more sick leaves than the host country population. However, these assumptions seem to go against the qualitative findings previously mentioned [17]. Thus, the need for quantitative analysis of the relationship between health and sickness absence patterns among the group of immigrant.

Furthermore, several studies find that the work environment conditions are important risk factors underlying sick leave, in particular studies related to the physical working environment [18-20]. A number of studies have shown that immigrants have worse work conditions, especially in terms of bullying and racial harassment [16, $21,22]$. Contrary to that, a recent study on immigrant workers' work environment in the elderly-care sector in Denmark shows that immigrants from Non-western countries report a better work environment than Danes [23].
According to Steers and Rhodes' [4] theoretical model, health status and being an immigrant could be factors associated with sickness absence. In their model, the ability and motivation to be at work influence attendance to work (or the contrary, their absence). For example, a person who has been involved in an accident or is sick is possibly unable to be at work. Other factors that may hinder his/her presence at work could be family situations or transportation problems. The second part of their model-motivation to be at work- is determined by a combination of two other factors: employee's job satisfaction (e.g. job scope, relationship with leadership and with work group); and various internal and external pressures to attend. They can be economic, social and psychological pressures. Steers and Rhodes point out 5 major pressures: a) market conditions; b) incentive, reward system; c) work group norms; d) individual work ethics; e) and organizational commitment. Situations of high unemployment, or difficulties in finding jobs would increase the pressure to maintain a good attendance to work.

Given the findings in terms of immigrants' health and qualitative findings about sickness absence and health in Denmark, and based on Steers and Rhodes' approach, the present study intends to look into both health and sickness absence patterns of immigrants. Although the relationship between sickness absence and health has been previously explored, in the medical sciences [3, 4], it is important to observe this relationship among the immigrant group because they are subject to different social, economic and psychological pressures $[4,24]$ than the native Danes may affect both their health and absenteeism. Furthermore, this study will be the first to look into the interactive effect between being an immigrant and health on sickness absence. Last but not least, this study seeks to shed light on immigrant's work environment and how health-related problems affect their work life.

\section{Aim and Research Questions}

The objective of the present study is to investigate patterns of sickness absence in light of health status among immigrants. In other words, our aim is to explore whether immigrants' health status is consistent with their sickness absence patterns. Hence, the research questions investigated in this study are the following:

1) Do elderly-care immigrant workers report having more health problems than Danes?

2) Do elderly-care immigrant workers have higher sickness absence than Danes working in the elder care sector? 
3) Would the associations between health indicators and sickness absence be different between the Danes and elderly-care immigrant workers?

Health status, as well as sickness absence, can provide significant insights into both social and psychological aspects related to the immigrant population [25]. Such information is not only relevant for public health and labor market but also for the work environment and integration policy making. This paper intends to enrich the limited knowledge presently available on these areas by looking into the elderly-care sector in Denmark.

\section{Methods}

\section{Survey Material}

The cross-sectional data used in this study stemmed from a national survey-the Danish Health Care Worker CohortClass of 2004 (DHCWC-2004). The dataset was from the first follow-up survey, carried out in 2005 in order to investigate the work environment and health in the elderlycare sector in the first year after graduation. The baseline dataset was composed of all students in Denmark in their last semester of technical education in elderly-care. In other words, respondents had graduated as healthcare assistants (HA) and healthcare helpers (HH) in 2004. ${ }^{1}$ Baseline response rate was $90 \%$. In 2006 , data for the second follow-up was collected in order to follow the respondents two years after graduation.

The follow-up questionnaire from 2005 used in our present analysis was administrated to 5,696 workers in that sector (all those that answered the baseline questionnaire). A total of 3,708 questionnaires were completed and return to the research team, comprising an overall $65 \%$ response rate. Given our interest in sickness absence, the study population was reduced to those working either as HAs or as HHs in 2005. Since a few respondents did not provide sufficient information to categorize their immigrant status, they were excluded from the study.

\section{Subjects}

The final sample used in this study consisted of 3,121 health care workers that answered the questionnaire. The respondents were mostly Danes (91\%) and $95 \%$ of the

\footnotetext{
1 The healthcare helper education takes 1 year and 2 months. The work of $\mathrm{HH}$ involves personal and practical work with users in their daily activities so that they can perform their normal practices. The healthcare assistant education takes 1 year and 8 months and can only be taken after completion of healthcare helper education. The work as a HA is related to coordination and teaching activities, along with basic health and nursing activities.
}

sample was female, which mirrored the gender distribution in this work sector. The sample mean age was 35.4 years (10.6 SD).

When looking at each ethnic group, we find that immigrants have significantly higher proportions of males $(P<0.001)$ than Danes and they have significantly higher mean age than the group of Danes $(37$ compared to 35 years of age) $(P<0.001)$.

Variables

\section{Dependent Variable}

Sickness absence-Participants were asked to report how many sickness-absence days they had taken in the past 12 months. Their responses were coded into 3 categories: low sickness absence ( $0-5$ sick absent days); moderate sickness absence (6-20 sick absent days) and high sickness absence (21 or more days). ${ }^{2}$

\section{Independent Variables}

Being an immigrant-In order to distinguish Danish respondents from immigrants, information about their citizenship, place of birth and parent's citizenship and place of birth was obtained from the Central Civil Register. This information was used to correct self-reported questionnaire information. Based on the Danish Bureau of Statistics' definition, a person was defined as a Dane, if at least one of the parents was both a Danish citizen and born in Denmark. A person was defined as immigrant in all other cases. Children of immigrants born in Denmark were here defined as immigrants given the fact that they were less than $1 \%$, too few to stand as a separate group, and considering that they possibly hold strong cultural ties to the parent's origin.

In Denmark, the group of immigrants comprised 8.5\% of the entire population, as per January 2006. The most common nationalities among the immigrant population were: Turkish (12\%), Iraqis (6\%), German (6\%), Lebanese $(5 \%)$ and Bosnian (4.5\%). Among those individuals participating in the labor force, immigrants corresponded to $7 \%$ and they were $6 \%$ of all individuals working in social institutions (elderly-care is a part of this branch) [26].

\footnotetext{
2 This definition would correspond to 1 week of sickness absence, 2 to 3 weeks of absence and 4 or more weeks. The reason behind this subdivision is due to administration reasons. The employer has up to 4 weeks after the first day of sickness absence to report the workers that were absent for more than 15 days to the municipality, in order to receive refunds from the employees' residence municipality for the costs related to the employee's absence. From that point sickness absence is administered at the municipality level as long-term sickness absence.
} 
In terms of our study population, the most common nationalities were: Polish $(21 \%)$, German (9.5\%), Norwegian $(8.5 \%)$, Bosnian (7.4\%) and Turkish (6.4\%).

\section{Health Indicators}

General Health-Participants were asked to indicate in a 5point Likert scale "How do you think your health is, all in all?". The multiple choice responses ranged from: (1) Excellent; (2) Real good; (3) Good; (4) Not so good; and (5) Poor. Their answers were dichotomised into poor health (which included values 4 and 5) and good health (all other values)

Back pain-Respondents were asked to report how many days in the last 12 months they had had back pain. In an attempt to distinguish the short periods of pain from long ones, the dichotomized independent variable corresponds to pain for 31 days and over and pain for less than 31 days.

Sleeping Problems-Respondents were presented with 4 questions measuring in a 5-point Likert scale their sleep quality. Those questions were: 'In the past 2 weeks, have you slept restlessly and bad?', 'In the past 2 weeks, have you had difficulties falling asleep?', 'In the past 2 weeks, have you woken up too early and not been able to sleep again?' and 'In the past 2 weeks, have you woken up several times and had difficulties falling asleep again?'. The questions were transformed into a scale (COPSOQ, [27]) that measures the quality of sleep. Its score ranges from 0 to 100 points, with high scores indicating high levels of quality of sleep. Sleep quality scale reliability was tested and Chronbach alpha evidenced internal consistency of the scale ( $\alpha=0.91$ ). The scale was then dichotomised in values expressing: sleeping problems (0) vs. no sleeping problems [1].

We acknowledge that sleeping problem is not a health problem per se and many times it is stress related. Nonetheless, sleep is an important factor for restitution. Lack of sleep can increase the risk of disease or add to previously existing health problems [28, 29].

\section{Control Variables}

Previous studies have reported that women and older age groups are more likely to have more sickness absence than their male and/or younger counterparts [9]. In line with these studies, age and gender were used as covariates in this study.

\section{Statistical Methods}

Due to the categorical nature of the independent variable 'sickness absence', a multinomial logistic regression was employed. Another possibility considered was an ordinal regression, but that was not used because the assumption that the probabilities are linear on the explanatory variables is not theoretically reasonable [30]. Three models were used: Model I, where the variable being an immigrant was included as the only predictor; Model II, where health indicators were included as predictors; and Model III, where the interaction between being an immigrant and health indicator was introduced in the equation.

Predicted probabilities are calculated from the multinomial regressions and are shown in Figs. 1, 2 and 3. Due to the difficulties in interpreting multinomial logistic regression results the multinomial regressions estimates was be converted into estimated probabilities. These measures are intuitively easier to understand because they do not need to be seen in light of reference categories. Predicted probabilities were generated from Model III for each individual in the study population. The average predicted probability of reporting the three levels of sickness absence for the groups of interest, i.e. for Danes and immigrants in separate health status groups, are here presented.

\section{Results}

\section{Descriptive Measurements}

The descriptive measures based on all variables of interest for both Danes and immigrants are presented in Table 1.

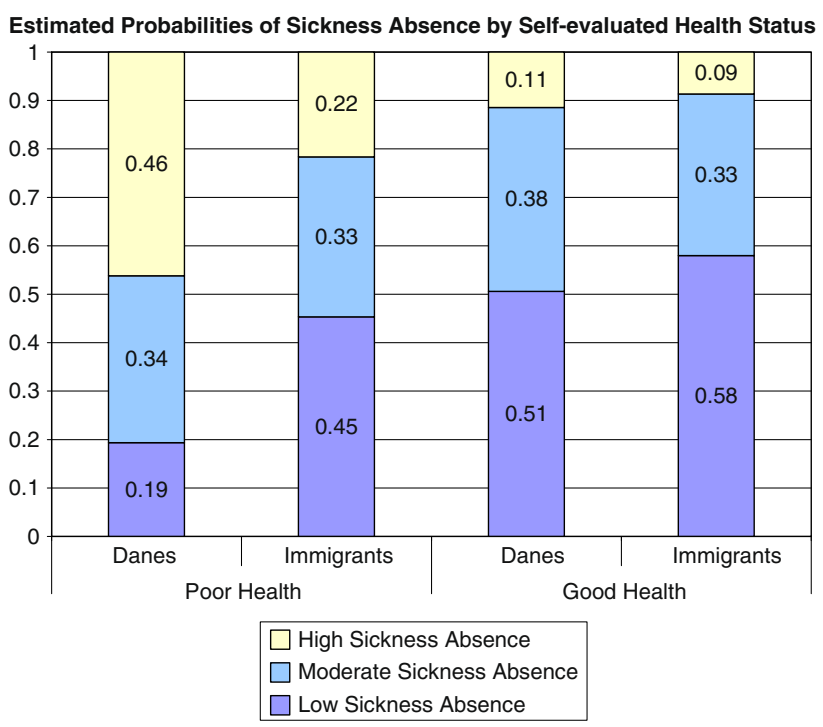

Fig. 1 Estimated probabilities by immigrant and health status. Note: The numbers in each bar represent the estimated probabilities of low, moderate and high sickness absence and they add up to 1 


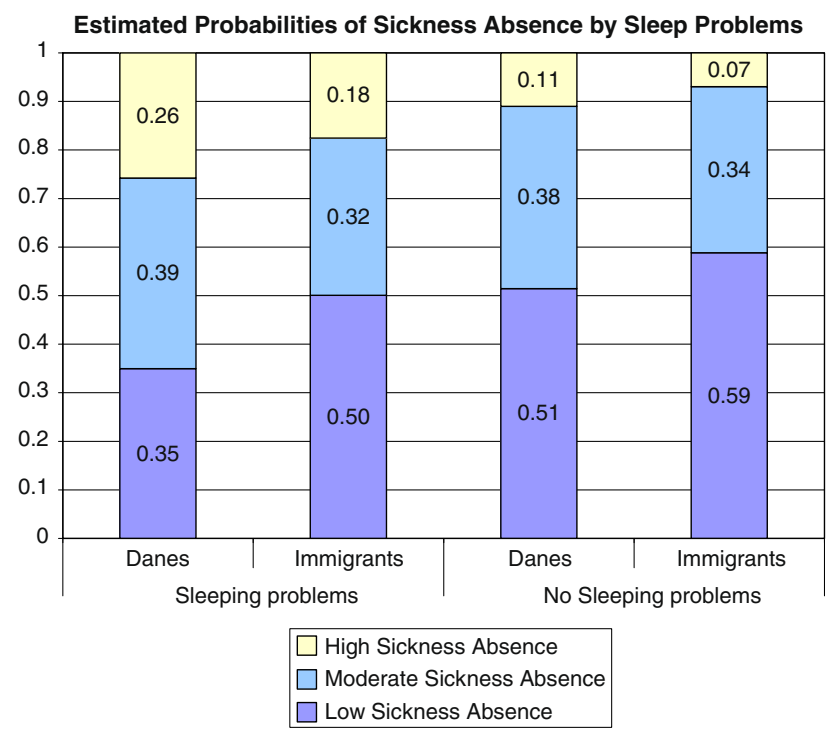

Fig. 2 Estimated probabilities by immigrant and sleep problems. Note: The numbers in each bar represent the estimated probabilities of low, moderate and high sickness absence and they add up to 1

Estimated probabilities of Sickness Absence by Back Pain Duration

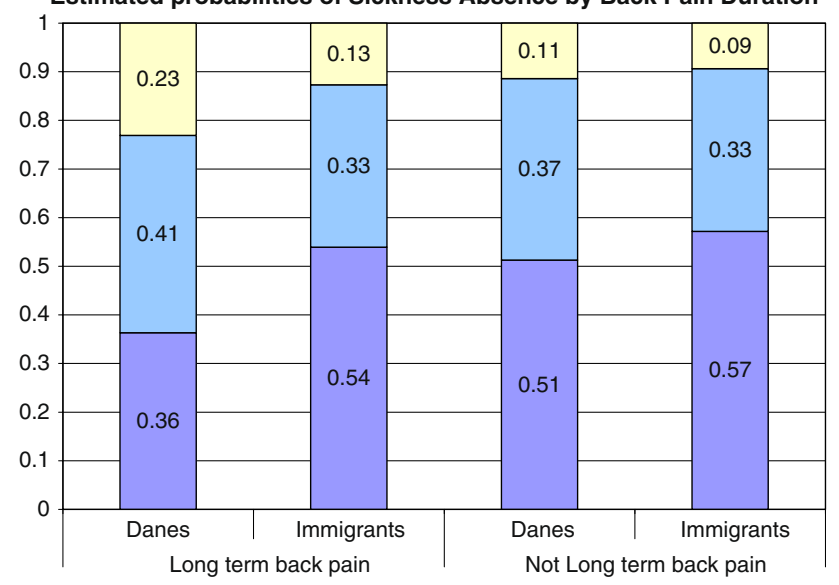

\begin{tabular}{|l|}
$\square$ High Sickness Absence \\
$\square$ Moderate Sickness Absence \\
$\square$ Low Sickness Absence
\end{tabular}

Fig. 3 Estimated probabilities by immigrant and back pain duration. Note: The numbers in each bar represent the estimated probabilities of low, moderate and high sickness absence and they add up to 1

\section{Sickness Absence}

The average number of sickness absence days reported was 14 days, but Danes reported on average 14.4 and immigrants reported 9.9 days absent from work due to illness. As can be seen in Table 1, lower proportions of immigrants reported high sickness absence (21 days or more), while a higher proportions of immigrants indicated low sickness absence ( $0-5$ days) in comparison to Danes. This difference in proportions of sickness absence experienced is significant $(P=0.007)$.
Table 1 Descriptive characteristic of Danes and immigrants

\begin{tabular}{llll}
\hline & $n$ & \multicolumn{1}{l}{$\begin{array}{l}\text { Danes (\%) } \\
\text { Immigrants (\%) }\end{array}$} \\
& 3,121 & $2,831(90.7)$ & \multicolumn{1}{l}{$290(9.3)$} \\
\hline $\begin{array}{l}\text { Gender } \\
\text { Female }\end{array}$ & 2,971 & $2,708(95.7)$ & $263(90.7)$ \\
Sickness absence & & & \\
Low (\%) & 1,509 & $1,353(48.6)$ & $156(56.9)$ \\
Moderate (\%) & 1,143 & $1,052(37.8)$ & $91(33.2)$ \\
High (\%) & 404 & $377(13.6)$ & $27(9.9)$ \\
$\begin{array}{l}\text { General health } \\
\text { Poor (\%) }\end{array}$ & 210 & $179(6.4)$ & $31(10.8)$ \\
Good (\%) & 2,879 & $2,622(93.6)$ & $257(89.2)$ \\
$\begin{array}{l}\text { Sleeping problems } \\
\text { Sleeping problems (\%) }\end{array}$ & 575 & $493(17.6)$ & $82(28.9)$ \\
No sleeping problems (\%) & 2,506 & $2,304(82.4)$ & $202(71.1)$ \\
Back pain & & & \\
31 or more days (\%) & 564 & $512(18.2)$ & $52(18.0)$ \\
Less than 31 days (5) & 2,301 & $2,301(81.8)$ & $237(82.0)$ \\
\hline
\end{tabular}

\section{Health Indicators}

As can be seen in Table 1, immigrants perceive their overall health differently than Danes $(P=0.006)$. A higher proportion of immigrants $(11 \%)$ indicated that they had poor health in comparison to Danes (6\%). In terms of sleeping problems, higher percentages of immigrants reported sleeping problems $(P<0.001)$. However, regarding back pain, there were no significant differences in terms of long-term back pain $(P=0.50)$.

Table 2 summarizes the results of the Multinomial logistic regression risk ratios for three different models.

The null hypothesis that all regression coefficients are equal to zero is rejected for all 3 models. Although Model I and II have significant Log Likelihood Ratio, Model III provides a better fit for each of the health status analyses developed. That is given by the improvement in Chi-square from Model I to Model III. The respective LLR chi-square for the analysis on self-reported health, for example, is 120.5 (6 d.f.), 225.4 (8 d.f.) and 259.2 (10 d.f.).

Although not presented in Table 2, age and gender were included in all the models and analyses. Age was a significant factor in all of them, but not gender. The older an individual is the higher the risk of sickness absence $(P<0.001$ in all three models for both moderate sickness absence as high sickness absence regressions).

Relative risks from Model I show that, although immigrants have lower relative risk of having moderate $(\mathrm{RRR}=0.80)$ or high sickness absence $(0.66)$ compared to low sickness absence, being an immigrant is not a significant factor in either the occurrence of moderate sickness absence or high sickness absence, as compared to low sickness absence. 


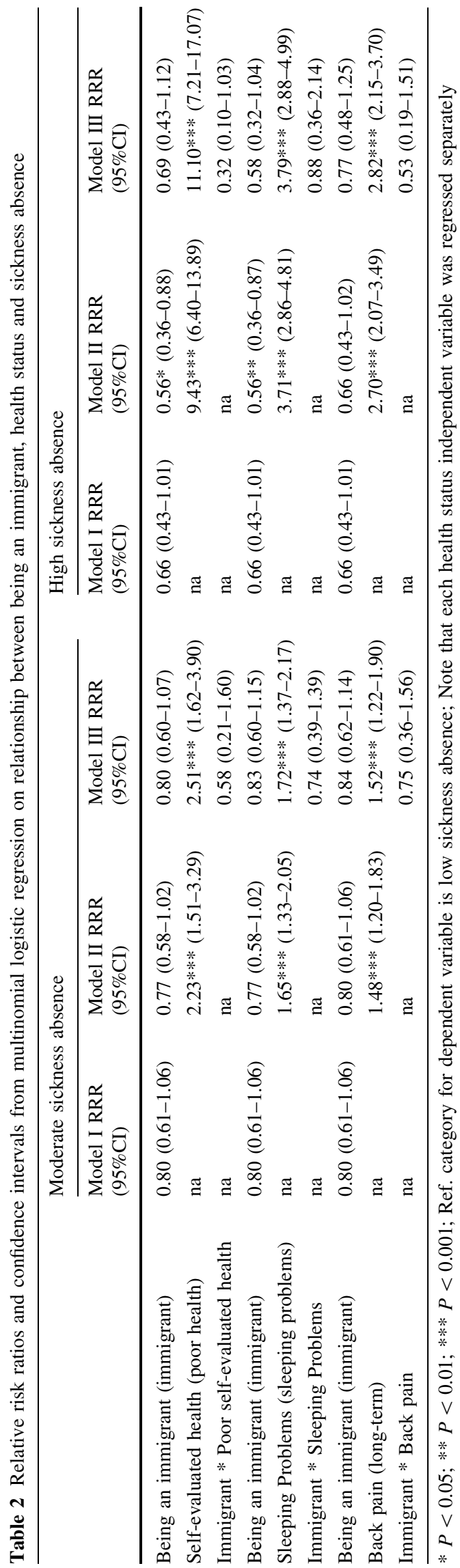

Three separate regressions for Model II were analysed (one for each health indicator). In all regressions, health indicators are significant factors for moderate and high sickness absence as compared to low; in other words, those reporting either poor health, sleeping problems or back problems had significantly higher risk of having moderate and high sickness absence than to those reporting otherwise. The inclusion of health in the models did not alter the direction nor modify much of the intensity of the effect of being an immigrant on moderate sickness absence. In other words, as in Model I, immigrants still have lower risk of moderate sickness absence, although the difference is not significant compared to low sickness absence. However, when high sickness absence is considered, being an immigrant becomes a significant factor in the models considering self-reported health and sleeping problems. That is to say that, when health status is controlled for (along with age and gender), being an immigrant tends to significantly decrease the risk of high sickness absence (RRR ranging from 0.56 to 0.66 in all three health indicators). Hence, when looking into self-reported health, the risk of immigrants having high sickness absence is $46 \%$ lower than that of Danes. Similarly, the risk of sickness absence is $46 \%$ and $34 \%$ lower for immigrants when controlled for sleeping quality and back-problems, respectively.

As can be seen in Table 2, in Model III, the risk of having moderate and high sickness absence for immigrants who reported poor health (interaction term) is $42 \%$ and $68 \%$ (respectively) lower than Danes reporting poor health. Similar results were obtained for those reporting sleeping problems and back problems. However, the interaction effect was not significant in any health status regressions in Model III. In the case of self-reported health status, the interaction effect was almost significant $(P=0.058)$, but not quite. It is possible that the lack of significance effect was due to small size of the group of immigrants, especially when the group is subdivided into health status groups.

Overall, Figs. 1, 2 and 3 presented for each health indicator show that Danes have higher probabilities of moderate and high sickness absence. Immigrants, on the other hand, have higher probabilities of having low sickness absence. The probabilities that Danes with health problem will have moderate and high sickness absence increases substantially compared to those reporting no problems. On the contrary, that probability does not increase much for immigrants.

Hence, when looking at the differences in probabilities between Danes and immigrants, the gap is much higher among those reporting health problems. Interestingly, in terms of self-evaluated health, there is a more pronounced difference between Danes and immigrants in terms of other 
health problems. Figure 1 shows that the group of Danes has a higher chance of experiencing high sickness absence $(P=0.024)$, whereas the latter has just as high a chance of experiencing low sickness absence. Similar pattern is also observed on following Figs. 2 and 3.

In summary, the estimated probabilities do not change much between immigrants with health problems or not. On the contrary, for Danes, there is a substantial increase in the probability of more sickness absence, by moving from a healthy status to a non-healthy one. The results indicate that the relationship between health status and sickness absence is quite distinct between Danes and immigrants, even if the interaction effect observed was not significant.

\section{Discussion}

This study looks into the relationship between health, sickness absence and being an immigrant. Our findings show that immigrants have worse health conditions than Danes, which has been a general finding in many countries according to the literature focusing on immigrants [31, 32]. Nonetheless, a very distinct finding in term of sickness absence was revealed by the present study. Immigrants in the elderly-care sector have lower sickness absence than their Danish counterparts, even after factors, such as age and gender are controlled for. Literature from other countries has shown different results for immigrants [9, 10], although a qualitative study in Denmark has shown same results as ours [11]. A possible explanation for the difference could be differences in sampling, given that the present study focus is on elderly-care workers.

When exploring the relationship between sickness absence and being an immigrant, we find that immigrants have lower risk of moderate and high sickness absence than Danes, although no significance was found. When controlling for health indicators, the risk of moderate and high sickness absence became even lower, for all health indicator in the regression analyses. The difference between Danes and immigrants became significant in terms of high sickness absence (particularly, when general health and sleeping problems are concerned). One can clearly see from the results that the relationship between sickness absence and being immigrant is influenced by health status. When introducing the interaction into the analysis, we observe that immigrants with poor health have lower risk of moderate and high sickness absence than Danes. For example, an immigrant that evaluates his/her health to be poor has $42 \%$ and $68 \%$ lower chance than Danes to have moderate and high sickness absence, respectively. However, the results showed no statistical significance, which we attribute to the small sample size because the differences between the two groups in terms of predicted probabilities are quite striking.
Our findings are in line with the theory of work attendance by Steers and Rhodes' $[4,5]$, indicating that work attendance is affected by the ability to be at work. We can see from our results that, undoubtedly, the ability to be at work (expressed by the health indicators) is a significant factor in sickness absence. In other words, one will be at work if one has no hindering circumstances, such as disease and transportation problem (all other factors aside). Indeed, health was the factor with strongest effect on sickness absence in our analyses. Those with poor health have a much higher risk of moderate and high sickness absence than those with good one, regardless of being an immigrant, age or gender.

Our results also show that the relationship immigrant and sickness absence is different for different health status. The probability of sickness absence for an immigrant is almost the same as the one for Danes, if we consider the 'healthy' group. However, 'unhealthy' immigrants have much less probabilities of moderate and high sickness absence than Danes. Indeed, the probabilities of sickness absence for 'healthy' immigrants are not so different than the probabilities for 'unhealthy' ones. When looking at Danes, on the other hand, there is a significant increase in the probabilities of moderate and high sickness absence from going from being 'healthy' to being 'unhealthy'.

The second part of Steers and Rhode theoretical model refers to 'other factors' that can affect job attendance. Although we did not test other factors, our results point in the direction of the possibility of other factors leading immigrants to be at work even when sick. According to their framework, unemployment or fear for loosing ones job could be one of these factors. In 2004, the year prior to the survey, the highest unemployment rate of the decade was registered in Denmark [4, 33]. Furthermore, a qualitative survey mentions the possibility that immigrants do not take sickness absence because they are careful about their present work situation. In one of the interviewees own words: 'Yes, they have less (sickness absence). I don't think it is because they are sick less often, but, as I said before, I think they take care of their job, once they have gotten one.' (author's translation) [11]. Another study has shown that having an income is a strong determinant for immigrant's well-being and employment was reported in association with feelings of pride, self-worth and satisfaction. The same study also mentioned the difficulties that immigrants face in finding jobs.

The immigrant's own family situation could be a source of pressure to attend. Immigrants have normally higher number of children. Indeed, there is a significantly higher percentage of households composed of a couple with children among immigrants than among Danes [17]. There is also lower insertion of immigrants in the labor market. It is possible that a working immigrant is supporting the 
family financially or at least partially supporting others. Hence, loosing a job or the fear of loosing it has a whole different meaning than for a Danish worker.

Another factor mentioned by the Steer's model is motivation. Immigrants from the sector have shown to experience higher degrees of influence, less work demands and they seem to be doing better than their Danish counterparts [23]. The fact that they to some degree experience their work environment in a better way than Danes can play a part in their decision-making in terms of attendance to work.

Work ethics is also one of the elements in the work attendance theory. It would be natural to assume that immigrants have different work ethics and believes related to the work place, one that is based on their country of origin. If sickness absence is seen by immigrants as something not well accepted and 'bad', immigrants will very likely go to work even if they are sick. Another possible explanation for their behaviour in terms of attendance is given by the Social Identity Theory [34]. According to this theory, 'out-group' members are under pressure to perform in a 'better' way in order to maintain a positive identity, which is based on positive comparisons between the in-group and the out-group. This perception could affect their work ethics and their behaviour.

\section{Strengths and Limitations}

The present study is based on a large population of recently graduated in $\mathrm{HH}$ and HA (technical education) in their first year of work. The survey had a good response rate (65\%), although a lower proportion of immigrants have participated than Danes (54\% compared to 66\%). A strong point of the analysis is its focus on a single labor market sector. In doing so, the population becomes more homogeneous, therefore the reduction of intervening factors (such as work branch and other job specific factors) that can occur when looking at different branches. As was previously seen, we observe different results in terms of sickness absence than other studies that have used a less homogeneous sample.

Nonetheless, this study has some limitations in its nature. First, it is a cross-sectional analysis, which cannot lead to any conclusion on causality of sickness absence. Nonetheless, our intention is to observe the patterns of sickness absence and health and their relationship in the immigrant group in that point in time, which was accomplished. Still, longitudinal analysis with appropriate data would indeed strengthen the findings. The second and third limitations are often found in analyses involving immigrants: (a) by taking the entire immigrant group as a block, one analyzes a very heterogeneous group, where many different nationalities and cultures are grouped; there is reason to believe that there are variations in the health patterns and the sickness absence between different immigrant groups; nonetheless, the sample size does not permit further subdividing this population. (b) and the size of the sample, which can limit the results, especially regression analyses. As could be seen, the relationship between ethnicity and sickness absence did not suffer much in those terms; however, the effect of the interaction term was possibly affected. This would lead to a type-II error of rejecting a relationship when in fact there was one. A larger sample of immigrant population working in the sector would possibly allow for a better subdivision of the immigrant population and/or increase the significance of the coefficients. Given the large differences in predicted probabilities, the direction of the effect would possibly still remain. Thus, there is need for providing tools to make their participation easier, and by doing so, improving the immigrant's response rate. Such tools could also focus on improving the semantic understanding of the question by immigrants (e.g. questionnaires translated to the major languages of immigrants in the host country). Furthermore, data collection specifically focusing on immigrants would lead to larger samples of that group, hence allowing for better and more complex analyses. Last but not least, the validity of the answers can be implicated if immigrants feel pressured to 'answer' in a positive way given their embedded work values and culture. It is a common fact that many of these foreign cultures are more hierarchic in many aspects, among them the work life, when compared to the Danish culture. Immigrants could be afraid to disclose their feelings on work- related factors and suffer reprimands or even loose their jobs because of it.

\section{Conclusion}

Sickness absence is a complex phenomenon and a common indicator of impaired health and lost productivity in organizations. To our knowledge, the present study is the first to look into how ethnicity affects the relationship sickness absence and health. It has shown that the expected direct relation between sickness absence and illness does not exactly hold for the group of immigrants. If on one side it could be quite positive to experience lower sickness absence because one is not often sick, it can be very problematic if one is pressured to come to work even when feeling sick. Studies have clearly shown the lack of recovery by being present at work while sick (presentism) is an important factor in ill health $[35,36]$, as well as on productivity itself [37]. Coping with other pressures by remaining at work while sick is not the answer to the pressure, much less to the disease at hand.

Further analyses of the group of immigrants, particularly in terms of their perceptions and beliefs related to the 
work-life, is necessary to further explore the reasons behind immigrant's behaviour toward their health and work-life. The present analysis will be complemented in the near future by looking at data from both the survey in 2005 and its follow-up in 2006 and analyzing sickness absence as a function of the ability to be at work (health factors) and the respondent's motivation to be at work, which can be measured via psycho-social work environment factors, such as work demands and meaning of work. These work environment factors can both be investigated the year prior to the absence, as well as the year of sickness absence, providing a comprehensive longitudinal view of the phenomena.

Acknowledgements The study was supported by a grant from the Danish Parliament (SATS 2004). The authors thank Bodil Holst for linguistic suggestions.

Open Access This article is distributed under the terms of the Creative Commons Attribution Noncommercial License which permits any noncommercial use, distribution, and reproduction in any medium, provided the original author(s) and source are credited.

\section{References}

1. Borg V, Clausen T, Frandsen CL, Winsløw JH. Psykisk arbejdsmiljø i ældreplejen (Publication in Danish: Psychosocial work environment in the elderly-care sector). København: Arbejdsmiljøinstituttet; 2005. Report No.: FOR-SOSU rapport nr. 4.

2. Michie S, Williams S. Reducing work related psychological ill health and sickness absence: a systematic literature review. Occup Environ Med. 2003;60(1):3-9.

3. Allebeck P, Mastekaasa A. Chapter 5 risk factors for sick leave general studies Scandinavian. J Public Health. 2004;32(5):49108.

4. Rhodes SR, Steers RM. Major causes of absenteeism rhodes SR and steers RM managing employee absenteeism. Addison-Wesley; 1990. p. 33-63.

5. Steers RM, Rhodes SR. Major influences on employee attendance - process model. J Appl Psychol. 1978;63(4):391-407.

6. Alexanderson K, Norlund A. Sickness absence-causes, consequences and physicians' sickness certification practice a systematic literature review by the swedish council on technology assessment in health care scandinavian. J Public Health. 2004;63:3-236.

7. Eden L, Ejlertsson G, Lamberger B, Leden I, Nordbeck B, Sundgren P. Immigration and socio-economy as predictors of early retirement pensions. Scand J Soc Med. 1994;22(3):187-93.

8. Kindlung H. Indvandrares Förtidspensioner Under 1990-Talet (Publication in Swedish: Immigrants Early Pension in the 1990s). RFV-Redovisar 2001;7.

9. Nilsson M. Differences and similarities in work absence behavior: - empirical evidence from micro data. Växjö University, Faculty of Humanities and Social Sciences, School of Management and Economics; 2005.

10. Gustafsson B, Österberg T. Ursprung och förtidspension (Publication in Swedish). In: Egenförsörjning eller bidragsförsörjning? Invandrarna, arbetsmarknaden och välfärdsstaten. 21 st ed. SOU; 2004. p. 57-102.
11. Miiler MM. Arbejdsmiljø og indvandrere - Erfaringer med rekruttering og fastholderlse (Publication in Danish: Work environment and immigrants). The Danish National Centre for Social Research; 2006. Report No:6, p. 13.

12. Indvandrere skal tage presset af arbejdsmarkedet (Publication in Danish: Immigrants shall take the pressure off the labor market). 2007. 29-11-0007. Internet Communication.

13. Indvandrere er mindre syge (Publication in Danish: Immigrants have less sickness). Politiken 15-6-2006.

14. Indvandrer i job klarer skærene (Publication in Danish: Immigrants at work pull through). Urban 10-7-2006.

15. Schläger DM, Rasmussen N and Kjøller M. Sundhedsforhold blandt etniske minoriteter-en litteraturgennemgang (Publication in Danish: Health among ethnic minorities - a literature review). Copenhagen: National Institute of Public Health; 2005.

16. National Institute of Public Health (Sweden). The relevance of birth place - the health of various immigrant groups in Sweden. 2002. Report No.: Summary series: 2002:4.

17. Deding M, Jacobsen V. Indvandreres arbejdsliv og familieliv (Publication in Danish: Immigrant's work and family life). The Danish National Centre for Social Research; 2006. Report No: 06:31.

18. Ala-Mursala L, Vahtera J, Kivimaki M, Kevin MC, Pentti J. Employee control over working times: associations with subjective health and sickness absences. J Epidemiol Community Health. 2002;56(4):272-8.

19. Eshøj P, Jepsen JR, Nielsen CV. Long-term sickness absence risk indicators among occupationally active residents of a Danish County. Occup Med-Oxford. 2001;51(5):347-53.

20. Frost B, Breddam E. Bendsen J, Carlsen HB, Trykker HU. Sygefravær i Relation Til Arbejdsmijø Og Familieforhold (Publication in Swedish:Sick Leave in Relation to Working Conditions and Family Structure). Ugeskr Læger 1995;157:285660.

21. Fox S, Stallworth LE. Bullying, racism, and power: an investigation of racial/ethnic bullying in the US workplace. J Vocat Behav. 2005;66:438-56.

22. Shields MA, Price SW. Racial harassment, job satisfaction and intentions to quit: evidence from the British nursing profession. Economica. 2002;69(274):295-326.

23. Giver H, Carneiro IG, Høgh A, Borg V. Arbejdsmiljøforhold for SOSU-uddannede indvandrere i Danmark (Publication in Danish: Work environment conditions for SOSU-educated immigrants in Denmark). København: Det Nationale Forskningscenter for Arbejdsmiljø; 2007. Report No: 7.

24. Castro AB, Gee GC, Takeuchi DT. Job-related stress and chronic health conditions among filipino immigrants. J Immigr Minor Health 2008. doi:10.1007/s10903-008-9138-2.

25. Ortega A, Carneiro IG, Flyvholm M. Descriptive study on immigrant workers in the Danish Elderly-care sector. J Immigr Minority Health (Submitted). May 2008.

26. Statistics Denmark. StatBank Denmark. 7-8-0008. Internet Communication.

27. Kristensen TS, Borritz M, Villadsen E, Christensen KB. The Copenhagen burnout inventory: a new tool for the assessment of burnout. Work Stress. 2005;19(3):192-207.

28. Hanse $\AA$, Hogh A, Persson R, Garde AH. Associations between bullying, witnessing bullying and sleep problems 6th. In: International Conference on Workplace Bullying Sharing our Knowledge; 2008.

29. Nilsson PM, Roost M, Engstrom G, Hedblad B, Bergund G. Incidence of diabetes in middle-aged men is related to sleep disturbances. Diabetes Care. 2004;27:2464-9.

30. DeMaris A. Regression with social data: modeling continuous and limited response variables. Hoboken, New Jersey: John Wiley \& Sons; 2004. 
31. Borrell LN, Dallo FJ. Self-rated health and race among hispanic and non-hispanic adults. J Immigr Minority Health. 2007;10:22938. doi:10.1007/s10903-007-9074-6.

32. Robertson E, Iglesias E, Johansson S, Sundquist J. Migration status and limiting long-standing illness. Eur J Pub Health. 2003;13:99-104.

33. United Nations Economic Commission for Europe (UNECE). 2007. Internet Communication.

34. Tajfel H, Turner JC. An integrative theory of intergroup conflict. In: Hatch MJ, Schultz M, editors. Organizational indentity: a reader. Massachussets: Oxford University Press; 2004. p. 56-65.
35. Aronsson G, Gustafsson K, Dallner M. Sick but yet at work. An empirical study of sickness presenteeism. J Epidemiol Community Health. 2000;54:502-9. doi:10.1136/jech.54.7.502.

36. Aronsson G, Svensson L, Gustafsson K. Unwinding, recuperation and health among compulsory school and high school teachers in Sweden. Int J Stress Manage. 2003;10(3):217-34.

37. Chatterji M, V CJ. Sickness, absenteeism, presenteeism and sick pay. Oxford Econ Pap. 2002;54:669-87. 